\title{
New year, new challenges
}

WELL, IT'S ANOTHER YEAR AND OUR NEW PRACTITIONERS CONtinue to be confronted with changes and challenges.

Bryan Gray continues to work in the Ridgeway Clinic (described previously) but has also been working in another small-format Shoppers Drug Mart (SDM) at the Fort William Clinic and at a full-sized SDM. He describes quite a contrast between the 3 settings. The Fort William clinic is an interesting scenario. The physicians are moving to a new location across town (where they'll be served by an independent pharmacy), so the pharmacy at Fort William has become very quiet. This has, however, allowed Bryan to meet some of the clinic staff with whom he has been interacting via phone and fax. One nurse asked, "Are you the same Bryan who works at Ridgeway?" The 2 physicians and the nurse then all said, "Oohhh, you're the pharmacist who's been sending us all the faxes from Ridgeway!" They laughed and told him to keep up the good work. Bryan feels it's nice to get that kind of recognition.

In reflecting back on his first 6 months in practice, Bryan describes now having a sense of "permanence" or "continuousness." As he puts it, "I'm now working at my career and profession ... which is lifelong. I am now a pharmacist." He describes a sense of belonging and says of his patients, "I am becoming part of their life-becoming their pharmacist."

He also admits to being naive about pharmacists' expanded scope of practice. He recognizes that the change is complex: imposed quotas and targets, integrating clinical services with dispensary duties, interacting with physicians and getting the rest of the pharmacy team to accept these changes are all challenges. Nevertheless, his plans for 2014 are to persevere.

Meanwhile, Reid McDonald and Anita Cumbleton have left Barrhead and moved to Calgary. They realize that in order to practise the way they want, they will have to own their own pharmacy. In the meantime, Anita has taken a position at a large chain store. She is finding the practice environment very different-she feels she is regarded as only a "prescription checker" and someone to deal with insurance issues and complaints. Not surprisingly, she doesn't feel she is having the same impact on patient's health and well-being. Reid is working at 2 independent pharmacies, helping them over the holiday season.

Reid and Anita have ambitious plans to open their own pharmacy in March. At this point, they are awaiting approval of their plans from the Alberta College of Pharmacists. This will be a small $1000-\mathrm{ft}^{2}$ pharmacy with a minimal front store and 2 examination/counselling rooms, located in Cochrane, Alberta (about 35 minutes west of Calgary, population 18,750).

In reflecting on his first 6 months in the "real world," Reid feels that "there is so much that we can do, but unfortunately, few pharmacists want to invest in that future." He feels a certain frustration with other pharmacists not embracing the expanded scope of practice. He feels that they are just "too comfortable and/or lazy-they would rather be told what to do by management." Anita has seen firsthand that the corporate hierarchy also seems to be a barrier to the uptake of pharmacists' scope of practice.

Those of you following along could probably have predicted some of these events. Finally, a large dose of reality, you might say. It certainly does appear that many different forces are conspiring to prevent pharmacists from providing patientcentred care. But as I've said before, what is inspiring about these young pharmacists is how they handle these challengeswith resilience and keeping their eye on the goal. 